\title{
An ethical paradox: the effect of unethical conduct on medical students' values
}

Robert C Satterwhite, William M Satterwhite III and Cam Enarson Georgia Institute of Technology and Wake Forest University School of Medicine, Winston-Salem, North Carolina, USA

\begin{abstract}
Objective-To report the ethical development of medical students across four years of education at one medical school.

Design and setting - A questionnaire was distributed to all four classes at the Wake Forest University School of Medicine during the Spring of 1996.

Participants-Three hundred and three students provided demographic information as well as information concerning their ethical development both as current medical students and future interns.

Main measurements-Results were analyzed using cross-tabulations, correlations, and analysis of variance.

Results-Results suggested that the observation of and participation in unethical conduct $t^{1}$ may have disparaging effects on medical students' codes of ethics with $35 \%$ of the total sample (24\% of first years rising to $55 \%$ of fourth years) stating that derogatory comments made by residents/attendings, either in the patient's presence or absence, were "sometimes" or "often" appropriate. However, approximately $70 \%$ of the sample contended that their personal code of ethics had not changed since beginning medical school and would not change as a resident.

Conclusions-Results may represent an internal struggle that detracts from the medical school experience, both as a person and as a doctor. Our goal as educators is to alter the educational environment so that acceptance of such behaviour is not considered part of becoming a physician.

(Fournal of Medical Ethics 2000;26:462-465)
\end{abstract}

Keywords: Ethics; ethical development; paradox; medical students; derogatory comments

In recent years, there has been a focused effort to describe the ethical development of medical students. ${ }^{2-7}$ To date, however, only two studies have attempted directly to assess how medical students perceive their ethical environment and what impact this environment has on their ethical development. ${ }^{18}$ One of these studies demonstrated that medical students observe as well as participate in unethical conduct, beginning as early as the first year in medical school. ${ }^{1}$
Yet questions remain concerning the influence of such exposure on medical students' systems of values. Although medical students admit to doing what they know is wrong, ${ }^{1}$ how does this environment affect their code of ethics, both currently and as future residents? How might their own observations of and participation in unethical behaviours affect their perceptions of the appropriateness and inappropriateness of such actions? This report examines these questions by reporting on the ethical development of medical students across four years of education at one medical school.

\section{Methods}

All 426 students enrolled in a single medical school were surveyed. Three hundred and three students responded: $90 \%$ of the first years (103), $83 \%$ of the second years (91), $52 \%$ of the third years (56), and $56 \%$ of the fourth years (53).

In addition to questions concerning student perception of unethical situations in the clinical setting, ${ }^{1}$ the survey asked about the conduciveness of the school environment to the open discussion of ethical concerns; the development of students' code of ethics, both currently and as future residents; the fostering and nurturing of their non-academic development, both as a person and as a physician, and their willingness to attend medical school again (see appendix for relevant survey questions). Like the study by Feudtner $\mathrm{et} \mathrm{al},{ }^{8}$ the survey intentionally did not define "unethical," thereby permitting us to assess what the students themselves perceived was unethical or wrong in their behaviour and that of attendings and house officers. Unlike the Feudtner study, we did not include illustrative clinical vignettes in order to keep the survey to no more than one page, front and back, and to avoid being directive as to what we the authors think is "unethical" conduct.

The survey was twice pre-tested on small groups of students for clarity, consistency, and thoroughness. The responses were analyzed using crosstabulations, correlations, and analysis of variance.

\section{Results}

While the fact that medical students observe and even participate in unethical conduct has been 
Table 1 Medical students'perceptions of the appropriateness of derogatory comments by year in school

\begin{tabular}{lllll}
\hline Year in school & Never & Rarely & Sometimes & Often \\
\hline 1 & $48.7 \%$ & $26.9 \%$ & $19.2 \%$ & $5.2 \%$ \\
2 & $40.3 \%$ & $38.8 \%$ & $16.7 \%$ & $4.2 \%$ \\
3 & $13.4 \%$ & $34.6 \%$ & $50.0 \%$ & $2.0 \%$ \\
4 & $9.8 \%$ & $35.3 \%$ & $50.9 \%$ & $4.0 \%$ \\
Total \% & $31.2 \%$ & $33.6 \%$ & $31.2 \%$ & $4.0 \%$ \\
\hline
\end{tabular}

Table 2 Medical students' perceptions of current and future personal codes of ethics by year in school

\begin{tabular}{llll}
\hline Year in school & Enhancement & Stayed the same & Erosion \\
\hline 1 & $28 \%(17 \%)$ & $72 \%(67 \%)$ & $0 \%(16 \%)$ \\
2 & $16 \%(16 \%)$ & $74 \%(70 \%)$ & $10 \%(14 \%)$ \\
3 & $24 \%(8 \%)$ & $67 \%(71 \%)$ & $9 \%(21 \%)$ \\
4 & $29 \%(25 \%)$ & $65 \%(67 \%)$ & $6 \%(8 \%)$ \\
Mean $\%$ & $24 \%(16 \%)$ & $70 \%(69 \%)$ & $6 \%(15 \%)$ \\
\hline
\end{tabular}

Note. Parentheses contain perceptions of personal code of ethics a resident.

reported elsewhere, ${ }^{1}$ the current analysis suggests that such exposure has a potentially disparaging effect on medical students' standards: $35 \%$ of the total sample stated that derogatory comments made by residents/attendings, either in the patient's presence or absence, were "sometimes" or "often" appropriate; $65 \%$ said they were "rarely" or "never appropriate". Time exacerbates this effect: as students' year in school increased, so too did their beliefs in the appropriateness of these derogatory comments. While only $24 \%$ of first year students stated that derogatory comments made about patients were sometimes or often appropriate, 55\% of fourth year students did so $(r=.32, p<.001)$ (see table 1). Using an analysis of variance, we found that there were significant differences $(\mathrm{p}<$ $.001)$ between year in school and acceptance of the appropriateness of derogatory comments. Specifically, significantly more third and fourth year students stated that these derogatory comments were appropriate than did the first and second year students.

When asked about their own personal code of ethics since beginning medical school, however, $70 \%$ of the students responded that it had "stayed about the same"; a similar percentage (69\%) also expected to maintain their ethical fortitude as interns/residents (see table 2). While nearly a quarter of those surveyed indicated that since beginning medical school their code of ethics had improved, only $16 \%$ thought it would improve as future interns/residents. While $6 \%$ indicated their code of ethics had declined since being in medical school, those that thought it would decline as future interns/residents increased to $15 \%$.

Seventy-six per cent found the school environment to be "somewhat conducive," "conducive," or "very conducive" to the open discussion of their ethical concerns; $24 \%$ found it "not very conducive" or "not at all conducive". A majority (77\%) reported that the school had done a good job of fostering and nurturing their non-academic devel- opment as a physician; $23 \%$ disagreed. However, less than half $(44 \%)$ thought the school had done a good job of fostering and nurturing their nonacademic development as a person; $56 \%$ did not. In addition, $86 \%$ said they would "still go to medical school if they had it to do all over again," $2 \%$ said "no," and $12 \%$ were "not sure".

\section{Discussion}

Our results reveal two interesting phenomena. First, they reveal the potentially disparaging effects of exposure to unethical situations; namely, the potential to perceive unethical conduct (ie, derogatory comments about patients) as appropriate. Second, they reveal an ethical paradox: medical students observe and even participate in unethical conduct ${ }^{1}$ yet, at the same time, most contend that their personal code of ethics has not and will not change. This is in contrast to the results found by the Feudtner study, in which $62 \%$ of third and fourth year students surveyed had "some principles eroded or lost" ${ }^{8}$ Furthermore, a large majority of our sample indicated that the medical school had done a good job of fostering and nurturing their non-academic development as a physician; almost half concurred in terms of their non-academic development as a person. However, the increasing acceptance of derogatory comments about patients from the first year to the fourth implies the exact opposite-namely, gradual ethical erosion over time.

There are multiple implications from these results. First, students' exposure to unethical situations within the clinical environment may motivate them to maintain separate codes of ethics, one personal and one as a physician. This suggestion is partially supported by the stated differences in students' non-academic development as a physician versus their development as a person. In addition, relative to their code of ethics as a medical student, fewer students indicated that their code of ethics as a resident would improve and more indicated that it would decline.

Second, exposure to the clinical environment may cause students to change their values, perhaps without their recognition of that change. This proposition is supported by the gradual acceptance of derogatory comments across years in school. In the same way that people change their attitudes to be more consistent with their behaviour, ${ }^{9}$ our results suggest that medical students are motivated to justify reasonably their observation of and participation in unethical behaviour. Accordingly, their code of ethics transforms so that it is in agreement with their behaviour, thereby creating a consistency between the two.

Third, these results may epitomise the medical students' resolution of the conflicting situations in which they find themselves during medical school: as inexperienced, less knowledgeable, and powerless members of the medical team, medical students occasionally may do what they think is unethical yet necessary for their survival or success, while at the same time believing that they are main- 
taining intact their own personal code of ethics which they will employ when they have the knowledge and power to do so as a practising physician. In support, a recent report by Testerman et al concluded that cynicism is highest among medical students as they struggle to develop coping skills in the complex and challenging medical environment, but that this cynicism decreases as residents and then as practising physicians when they become more knowledgeable, skilful, and adept at dealing with ambiguous and challenging medical and ethical situations. ${ }^{10}$

\section{Limitations and directions for future research}

One potential limitation concerns question \#4 of the survey, which asks about the appropriateness of derogatory comments made both in the patient's presence and outside the patient's presence. Arguably, even accurate descriptive comments such as "the patient is morbidly obese" may always be inappropriate when made in the patient's presence, and perfectly appropriate as a medical description made outside the patient's presence. Yet few would contend that a statement like, "that patient is as fat as a cow," is ever appropriate even outside the patient's presence. Question \#1 of the survey assumed that medical students could distinguish between obviously derogatory comments and appropriate descriptions of patients - even if such descriptions were unflattering.

The present study is also limited both by the cross-sectional nature of its sample as well as by the fact that the third and fourth year students were not as well represented as the first and second year students. In regards to the former limitation, a four-year longitudinal study tracking the moral development (or erosion) of one class would obviously be optimal. In regards to the latter, it is possible that the third and fourth year students who did respond to the survey do not represent the values and beliefs of the majority. That is, had a larger percentage of third and fourth year students responded, it is possible that their perceptions might not be any different from those of the first and second year students.

However, $20 \%$ of the first and second year students, who were well represented in the sample, stated that derogatory comments made about patients were sometimes or often appropriate. Moreover, Satterwhite and colleagues have reported that, though a higher percentage of third and fourth year students were exposed to one or more unethical situations, over $20 \%$ of first and second year medical students reported observing and participating in unethical conduct. ${ }^{1}$ Thus, the paradox of observing and participating in unethical conduct while, at the same time, stating that their personal codes of ethics have not and will not change is not just true of the third and fourth year classes of medical students.

A four-year follow up study is currently being undertaken to understand the foundations of this ethical paradox. For example, do medical students maintain two different codes of ethics, one as a person and one as a physician in training? Do medical students consider exposure to unethical situations an unavoidable part of becoming a doctor? Does exposure to unethical situations detrimentally affect medical students' code of ethics?

However, whatever the basis for this ethical paradox, the implications of our results must not be taken lightly, for they may represent an internal struggle that detracts from the medical school experience, both as a person and as a doctor. Furthermore, our goal as educators must be to alter the educational environment so that acceptance of such behaviour is not considered part of becoming a physician.

\section{Appendix A Questions from the Medical School Ethics Survey}

For questions 1-2, how many times have you heard an intern/resident or an attending physician speak derogatorily about a patient, either:

1. - in the patient's presence:
a) 0
b) $1-2$
c) 3-7
d) $8-10$
e) $>10$
a) 0
b) $1-2$
c) $3-7$
d) $8-10$
e) $>10$

If you have heard derogatory comments as noted in either question 1 or 2 , how often do you find these comments to be appropriate?

$\begin{array}{llll}\text { a) never } & \text { b) rarely } & \text { c) } & \text { d) often }\end{array}$

4. How conducive is the medical school environment to the open discussion of your ethical concerns?

$\begin{array}{lllll}\text { a) very } & \text { b) } & \text { c) } & \text { d) not very } & \text { e) not at } \\ \text { conducive } & \text { conducive } & \begin{array}{l}\text { somewhat } \\ \text { conducive }\end{array} & \text { conducive } & \text { all } \\ \text { conducive }\end{array}$

5. Since being in medical school, do you think your personal code of ethics has been:

a) b) stayed c) eroded

enhanced about the

same

6. When you are a resident, do you think your personal code of ethics is most likely to:

$\begin{array}{lll}\text { a) decline } & \text { b) stay } & \text { c) improve }\end{array}$ about the same

For questions $7-8$, do you think this school has done a good job of fostering and nurturing your non-academic development as a:

$\begin{array}{lll}\text { 7. Person: } & \text { a) Yes } & \text { b) No }\end{array}$

9. If you had it to do all over again, would you still go to medical school?

$\begin{array}{lll}\text { a) Yes } & \text { b) Not } & \text { c) No }\end{array}$

sure

Robert C Satterwhite, PhD, is an Industriall Organisation Psychologist at Applied Psychological Techniques, Darien, Connecticut, USA. William M Satterwhite III, MD, is a Paediatrician in private practice, at Winston-Salem Pediatrics, North Carolina, USA. Cam Enarson, MD, is Associate Dean for Medical Education, Wake Forest University School of Medicine, Winston-Salem, North Carolina, USA.

\section{References}

1 Satterwhite WM III, Satterwhite RC, Enarson CE. "Doing what I know is wrong"- - a survey on unethical conduct at one medical school. Academic Medicine 1998;73:529-31. 
2 Bickel J. Medical students' professional ethics: defining the problems and developing resources. Academic Medicine 1991 66:726-9.

3 Christakis DA, Feudtner C. Ethics in a short white coat: the ethical dilemmas that medical students confront. Academic Medicine 1993;68:249-54.

4 Feudtner C, Christakis DA. Making the rounds: the ethical development of medical students in the context of clinical rotations. Hastings Center Report 1994;1:6-12.

5 Hafferty FW, Franks R. The hidden curriculum, ethics teaching, and the structure of medical education. Academic Medicine 1994;8:61-71.

6 Dwyer J. Primum non tacere. An ethics of speaking up. Hastings Center Report 1994; 1:13-18.
7 Bickel J. Proceedings of the AAMC Conference on Students' and Residents' Ethical and Professional Development. Academic Medicine 1996;71:622-40.

8 Feudtner C, Christakis DA, Christakis NA. Do clinical clerks suffer ethical erosion? Students' perceptions of their ethical environment and personal development. Academic Medicine 1994;69:670-9.

9 Kunda Z. The case for motivated reasoning. Psychological Bulletin 1990;108:480-98.

10 Testerman JK, Morton KR, Loo LK, Worthley JS, Lamberton $\mathrm{HH}$. The natural history of cynicism in physicians. Academic Medicine 1996;71:s43-5. 